\title{
The potato $R$ locus codes for dihydroflavonol 4-reductase
}

\author{
Yongfei Zhang • Shuping Cheng • Darlene De Jong • \\ Helen Griffiths $\cdot$ Rayko Halitschke $\cdot$ Walter De Jong
}

Received: 3 March 2009 / Accepted: 21 June 2009 / Published online: 9 July 2009

(C) The Author(s) 2009. This article is published with open access at Springerlink.com

\begin{abstract}
The potato $R$ locus is required for the production of red pelargonidin-based anthocyanin pigments in potato (Solanum tuberosum L.). Red color also requires tissue-specific regulatory genes, such as $D$ (for expression in tuber skin) and $F$ (expression in flowers). A related locus, $P$, is required for production of blue/purple anthocyanins; $P$ is epistatic to $R$. We have previously reported that the dihydroflavonol 4-reductase gene $(d f r)$ co-segregates with $R$. To test directly whether $R$ corresponds to $d f r$, we placed the allele of $d f r$ associated with red color under the control of the CaMV 35S promoter and introduced it into the potato cultivar Prince Hairy (genotype $d d d d$ rrrr $P$-), which has white tubers and pale blue flowers. Transgenic Prince Hairy tubers remained white, but flower color changed to purple. Three independent transgenic lines, as well as a vectortransformed line, were then crossed with the red-skinned variety Chieftain (genotype $D$ - $R$-pppp), to establish populations that segregated for $D, R, P$, and the $d f r$ transgene or empty vector. Markers were used to genotype progeny at $D$ and $R$. Progeny carrying the empty vector in the genetic background $D$-rrrr produced white or purple tubers, while progeny with the same genotype and the $d f r$ transgene produced red or purple tubers. HPLC and LC-MS/MS analyses of anthocyanins present in Chieftain and in a
\end{abstract}

Communicated by R. Waugh.

Y. Zhang $\cdot$ S. Cheng $\cdot$ D. De Jong $\cdot$ H. Griffiths $\cdot$ W. De Jong $(\bowtie)$ Department of Plant Breeding and Genetics, Cornell University, Ithaca, NY 14853, USA

e-mail:wsd2@ cornell.edu

R. Halitschke

Department of Ecology and Evolutionary Biology,

Cornell University, Ithaca, NY 14853, USA red-skinned progeny clone with the $d f r$ transgene in a $D$-rrrr background revealed no qualitative differences. Thus, $d f r$ can fully complement $R$, both in terms of tuber color and anthocyanin composition.

\section{Introduction}

The potato $R$ locus, first described by Salaman (1910), is required for the production of red anthocyanin pigments in any tissue of a potato plant. The related $P$ locus (Salaman 1910 ) is required for production of purple anthocyanins. $P$ has been shown to code for the anthocyanin biosynthetic enzyme flavonoid $3^{\prime}, 5^{\prime}$-hydroxylase (Jung et al. 2005). $R$ and $P$ are, nevertheless, not sufficient for red and purple color, respectively; both require the activity of additional tissue-specific regulatory genes such as developer $(D)$ (Salaman 1910) for anthocyanin production in tuber periderm or $F$ for anthocyanin synthesis in flowers (Dodds and Long 1956). $D$ is also known as the $I$ locus in diploid potato (Dodds and Long 1955, 1956). $P$ is known to be epistatic to $R$ (Dodds and Long 1955).

We have previously reported that a specific allele of dihydroflavonol 4-reductase ( $d f r$, another anthocyanin biosynthetic gene, was present in every red-skinned or redflowered potato clone examined (De Jong et al. 2003a), and absent in many, but not all, white potato clones. This result provided strong circumstantial evidence, but did not prove, that $R$ codes for $d f r$.

DFR catalyzes an essential reaction in each of the three primary branches of anthocyanin synthesis, reducing dihydrokaempferol (DHK), dihydroquercitin (DHQ), and dihydromyricetin (DHM) en route to the production of red pelargonidin, pink cyanidin, and purple delphinidin-based anthocyanins, respectively (Holton and Cornish 1995). 
In some genera, like Gerbera, DFR is able to efficiently reduce all three substrates (Johnson et al. 2001), while in other genera, like Petunia (Forkmann and Ruhnau 1987) and Cymbidium (Johnson et al. 1999), DFR can efficiently reduce DHQ and DHM, but not DHK. The precedent of differences in substrate specificity between species provides a possible explanation for how variation between alleles of potato $d f r$ might lead to differences in potato color; it suggests that the 'red allele' of potato DFR is capable of reducing DHK, while other potato DFR alleles cannot (De Jong et al. 2003a). Simple RFLP banding patterns suggest that $d f r$ is a single copy gene in both potato and tomato (De Jong et al. 2003a; Bongue-Bartelsman et al. 1994).

To test the relationship between $R$ and $d f r$ more thoroughly, we report here on the construction and evaluation of transgenic potato lines that express the 'red allele' of $d f r$, and show that this allele is able, in a genetic background that includes $D$, to direct synthesis of red pelargonidinbased anthocyanin pigments in tuber skin.

\section{Materials and methods}

\section{Plant materials}

Diploid potato clone 320-02 (kindly provided by H. De Jong, AAFC, Fredericton, NB) and tetraploid potato cultivars Prince Hairy (also known as NYL235-4) (Plaisted et al. 1992) and Chieftain (Weigle et al. 1968) were propagated as sterile plantlets in vitro, as well as via tubers in both the greenhouse and field. Transformed plants were maintained in the greenhouse under $14 \mathrm{~h}$ photoperiod and at temperatures of $24-28^{\circ} \mathrm{C}$ during the day and $16-18^{\circ} \mathrm{C}$ at night. Tubers were harvested after the vines had naturally senesced.

\section{Transformation construct}

The open reading frame of the potato $d f r$ allele that co-segregates with red color (De Jong et al. 2003a) was amplified from diploid W5281.2, which is homozygous $R R$, with primers DFRadaptorF (5' GCG CCA TGG CAA GTG AAG TTC AT) and DFRadaptorR (5' CGC GGT ACC CTA GAT TTC ACC ATT GGT). The fourth through ninth nucleotides of primer DFRadaptorF create an $N c o$ I restriction site, while the last 18 nucleotides correspond to the first 18 nucleotides of the $d f r$ open reading frame. The fourth through ninth nucleotides of primer DFRadaptorR create a $K p n I$ site, while the last 18 nucleotides anneal to the final 18 nucleotides of the $d f r$ open reading frame. The resulting PCR product was digested with $N c o \mathrm{I}$ and $K p n \mathrm{I}$, and then cloned into the $N c o \mathrm{I}$ and $K p n \mathrm{I}$ sites of intermediate vector pIBT210.1 (Haq et al. 1995). The $d f r$ open reading

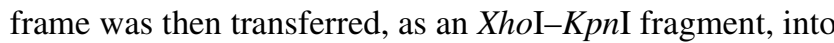
the XhoI and KpnI sites of binary vector pPS1 (Huang and Mason 2004). This vector drives expression with a doubled CaMV 35S promoter and carries a tobacco etch virus translational enhancer to further increase transgene expression. Sequencing the transgene construct revealed a single, translationally silent nucleotide change in the open reading frame: the 256th codon of the $d f r$ construct is CAT, while the same codon of native $d f r$ is CAC; both code for the amino acid histidine. The construct was introduced into Agrobacterium tumefaciens strain LBA4404, and then transformed into potato cultivar Prince Hairy as described earlier (Jung et al. 2005).

\section{Crossing}

Four transgenic Prince Hairy lines-three transformed with the $d f r$ construct, and one transformed with an empty pPS1 vector-were crossed, as females, to Chieftain. Seeds from the four crosses were harvested and planted in the greenhouse the following year. Approximately, 200 seeds from each of the three plants transformed with $d f r$ and the line transformed with an empty vector were sown.

\section{Genotyping}

Genomic DNA was isolated from $353 \mathrm{~F}_{1}$ progeny of the three crosses to $d f r$-transformed lines and $87 \mathrm{~F}_{1}$ progeny from the cross to the empty vector-transformed line using a quick extraction method (Edwards et al. 1991). PCR assays were used to genotype progeny at the $D$ and $R$ loci, and for the presence/absence of the transgene or empty vector. To test for the presence of the native allele of $d f r$ associated with red color, DNA was amplified with primers potDFR1 and potDFR2, and digested with BamHI (De Jong et al. 2003a). The same assay was used to test for the presence of the $d f r$ transgene; because the transgene lacks introns, amplification with the same primers yields smaller products. To test for the presence of $D$, DNA was amplified with primers 21BAClaI-F2 (5' GTG ATT ATG TCA TCC AAA AGT TTA TAG) and 21BAClaI-R1 (5' GAA TTT CTG AGG TTG AGG TCT TA), and digested with Cla I; these primers amplify part of an R2R3MYB gene tightly linked to $D$ (Jung and De Jong, unpublished). To test for the presence of the empty vector, DNA was amplified with primers pPS13162F (5' CGA ATC TCA AGC AAT CAA GCA) and pPS13443R (5' CGT AGG TAC GTG GAG TGT CTT); these flank the cloning sites of pPS1 and amplify a 282-bp product from an empty vector. PCR products were visualized on a $2 \%$ agarose gel. A total of 293 plants from all four crosses were selected based on genotype data generated by these markers. These were grown to maturity, when tuber color was recorded. 
Anthocyanin extraction

One-tenth of a gram of tuber periderm tissue was frozen in liquid nitrogen and ground to a fine powder. Anthocyanins were extracted using $1 \mathrm{ml}$ of $1 \%(\mathrm{v} / \mathrm{v}) \mathrm{HCl}$ in methanol for $5 \mathrm{~min}$. The homogenate was centrifuged for $10 \mathrm{~min}$ at $12,000 \mathrm{~g}$. The supernatant was filtered through a $0.45-\mu \mathrm{m}$ regenerated cellulose syringe filter (Grace, Deerfield, IL) prior to HPLC analysis.

HPLC analysis

Anthocyanin compounds were analyzed using a HP1100 Liquid Chromatograph equipped with a diode array detector (DAD) (Agilent Technology, Palo Alto, CA, USA). An Inertsil ODS-3 column $(5.0 \mu \mathrm{m}$ particle size, $4.6 \mathrm{~mm} \times 250 \mathrm{~mm}$, GL Sciences Inc., Tokyo, Japan) was used in the separation preceded by an Inertsil ODS-3 Guard Column $(5.0 \mu \mathrm{m}, 4.0 \mathrm{~mm} \times 10 \mathrm{~mm})$. Five microliter of filtered supernatant was injected for HPLC. A binary gradient of a mixture of water-acetonitrile-formic acid was used. Solvent A was $10 \%$ (v/v) formic acid in water and solvent B was $10 \%(\mathrm{v} / \mathrm{v})$ formic acid in acetonitrile. The gradient for HPLC analysis was linearly changed as follows (total $75 \mathrm{~min}): 95 \% \mathrm{~A}(0 \mathrm{~min}), 85 \% \mathrm{~A}(25 \mathrm{~min})$, $78 \%$ A (42 min), 64\% A (60 min), 95\% A (65 min). Post run-time was $10 \mathrm{~min}$. Flow rate was $1.0 \mathrm{ml} / \mathrm{min}$ at $30^{\circ} \mathrm{C}$. Anthocyanins of each sample were compared by their UV-vis spectra and retention times. A DAD chromatogram was generated using $520 \mathrm{~nm}$ as the detection wavelength.

\section{LC/MS analysis}

HPLC-MS/MS analyses on a Quantum Access triple quadrupole system (Thermo Finnigan LLC, San Jose, CA) was used to confirm anthocyanin identity. Anthocyanin extracts were separated on a ThermoFisher Accela HPLC equipped with a Gemini C18 reversed phase column (3 $\mu \mathrm{m}$, $150 \times 4.6 \mathrm{~mm}$, Phenomenex, Torrance, CA) using a solvent gradient (solvent $\mathrm{A}: 0.1 \%$ formic acid in water, solvent B: $0.1 \%$ formic acid in acetonitrile): $0-4 \mathrm{~min} 5 \%$ B, $24 \mathrm{~min}$ $60 \% \mathrm{~B} ; 34 \min 95 \% \mathrm{~B}, 40 \mathrm{~min} 95 \% \mathrm{~B}$ at a flow rate of $0.7 \mathrm{~mL} \mathrm{~min}^{-1}$. The MS detector was equipped with an electrospray ionization (ESI) probe operated under the following conditions: spray voltage $4.5 \mathrm{kV}$, capillary temperature $300^{\circ} \mathrm{C}$, sheath gas $\left(\mathrm{N}_{2}\right)$ pressure 30 arbitrary units, auxiliary gas $\left(\mathrm{N}_{2}\right)$ pressure 55 arbitrary units. Mass spectra were recorded in positive mode between $\mathrm{m} / \mathrm{z}, 100$ and $\mathrm{m} / \mathrm{z}, 1200$ to determine molecular ions $[\mathrm{M}+\mathrm{H}]^{+}$. Aglycone and glycosylation pattern were analyzed by collision-induced dissociation (CID energy $30 \mathrm{~V}$, CID gas (Ar) pressure 1.5 mTorr) of selected molecular ions and compared with reported anthocyanin fragmentation data (Eichhorn and Winterhalter 2005).

\section{Results}

To test if the allele of $d f r$ associated with red color corresponds to $R$, we introduced it, under the control of a doubled CaMV $35 \mathrm{~S}$ promoter and tobacco etch virus translational enhancer, into the potato cultivar Prince Hairy. Wild type Prince Hairy produces white tubers and pale blue flowers (Fig. 1). The blue flower color indicates that Prince Hairy must have a functional allele at the $P$ locus (genotype $P$-). In addition, because Prince Hairy tubers are white, this cultivar must lack a functional allele at $D$ (genotype $d d d d$ ). It has previously been shown that Prince Hairy lacks the allele of $d f r$ associated with red color (De Jong et al. 2003a). We would have preferred to introduce the red allele of $d f r$ directly into a white potato with genotype $D$-rrrr pppp, to test if the transformation would change skin color from white to red, but did not have such a genotype available. Thus an indirect approach, one that required subsequent crossing, was used in this study instead.

If $d f r$ corresponds to $R$, we anticipated that flower color would change in transgenic Prince Hairy, from light blue to purple, as the flowers would produce a mixture of blue and red pigments. Indeed, of the 12 independent transgenic Prince Hairy lines generated, 10 exhibited purple flowers (Fig. 1). Flower color in the remaining two transgenic lines was unchanged, presumably because $d f r$ was not expressed, or was expressed rather weakly. None of the seven independent Prince Hairy lines transformed with an empty vector developed purple flowers; all their flowers remained pale blue. Tubers of all transgenic Prince Hairy lines, whether transformed with $d f r$ or an empty vector, were invariably white (Fig. 1).

To determine how the red allele of $d f r$ would interact with $D$, three independent transgenic Prince Hairy lines, all with purple flowers, were crossed (as females) with the redskinned cultivar Chieftain, which is known to be simplex at $R$ (genotype D-Rrrr pppp) (De Jong et al. 2003b). We anticipated that the progeny of these crosses would segregate for native $R$ as well as the $d f r$ transgene, and would likely segregate for $D$ and $P$ as well. The progeny of most interest would be those that carried the transgene in a genetic background of D-rrrr pppp, as their phenotype would allow us to determine if $d f r$ could substitute for $R$. As a control, a Prince Hairy line transformed with an empty vector was also crossed with Chieftain.

Progeny of these three crosses were genotyped with PCR assays to assess the presence of $R$, the presence of the transgene or empty vector, and the presence of an R2R3 MYB gene tightly linked to $D$ (see "Methods"). All eight possible 
Fig. 1 Tubers and flowers of the cultivar Prince Hairy, before and after transformation with the 'red allele' of potato dihydroflavonol 4-reductase
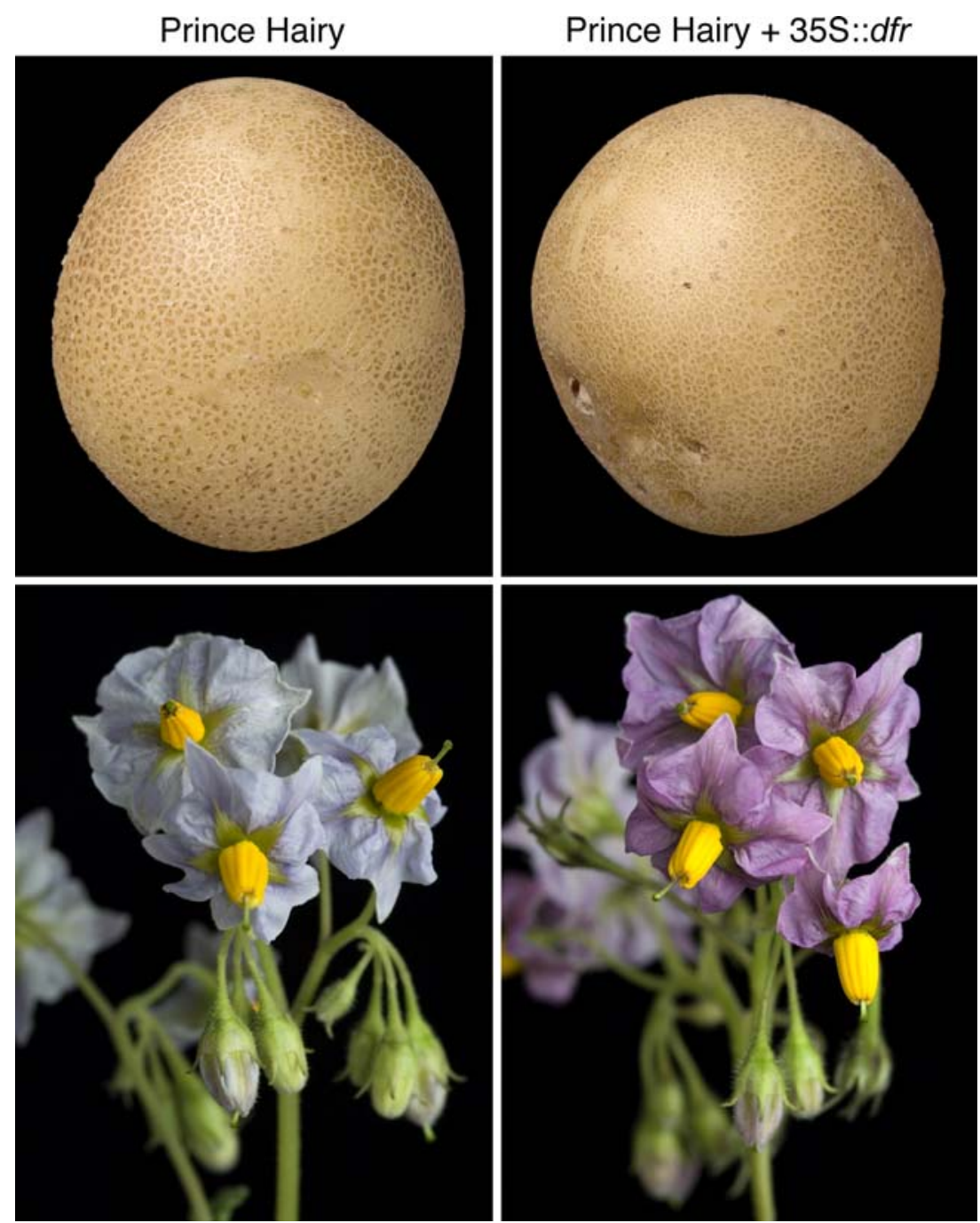

combinations of these loci were observed. The phenotype(s) observed for each genotypic class are summarized in Fig. 2. Because the three crosses with lines carrying the $d f r$ transgene yielded similar results (not shown), data from these three crosses were pooled in Fig. 2c. Note that the $P$ locus was not genotyped in this study.

As expected, all progeny lacking the marker tightly linked to $D$ produced white tubers, reflecting the requirement of $D$ for red or purple tuber skin. Progeny with this marker were red, purple, or white, presumably reflecting offspring that contained $R$ but not $P, P$ with or without $R$, and neither $R$ nor $P$, respectively (Fig. 2). The genotype of most interest was that which contained $D$ and the transgene, but lacked $R$. If $d f r$ corresponds to $R$, segregants with this genotype should be red or purple, but never white. Of 62 clones with this genotype, 28 red- and 34 purple-skinned clones were observed, and no clone produced white tubers (Fig. 2c). Of the six progeny that carried $D$ and the empty vector, but lacked native $R$, four produced purple tubers, and two produced white tubers; none produced red tubers (Fig. 2d). Thus, the allele of $d f r$ that co-segregates with $R$, but not an empty vector, can complement $R$.

Since $D$ appeared to segregate in a 5:1 ratio when the data from all four crosses were considered together (239 colored:54 white, $\chi^{2}=0.66, P=0.42$ ), Chieftain appears to be duplex for $D$ (i.e., genotype $D D d d$ ). Similarly, since the skin color of all progeny combined with $D$ and native $R$ segregated in an apparent 1:1 ratio (54 red:69 purple, $\left.\chi^{2}=1.83, P=0.18\right)$, Prince Hairy appears to be simplex at the $P$ locus.

To determine if the anthocyanins produced in red untransformed tubers with genotype $D$ - $R$ - were comparable in composition to those produced in red tubers expressing the $d f r$ transgene, pigment profiles were compared by HPLC. As shown, the red-skinned variety Chieftain and a transgenic progeny clone with genetic background $D$-rrrr (i.e., lacking native $R$ ) produced indistinguishable pigment profiles (Fig. 3). Both were clearly distinct from the 
Fig. 2 Predicted and observed tuber color, sorted by genotype, in $F_{1}$ progeny of crosses between transgenic Prince Hairy and Chieftain. a, b The PCR assays used to genotype at $R / d f r$ and $D$, respectively. c, d Predicted and observed tuber color for each genotype where the transgene is the 'red allele' of $d f r$ in (c), and an empty vector in (d). Representative tubers for each genotype are shown on the right side of panels (c) and (d)

\section{A}

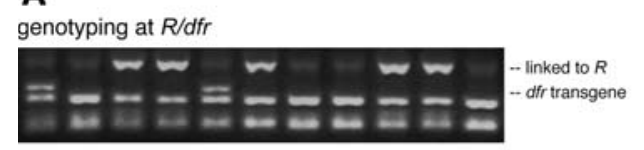

C

predicted / observed tuber color; transgene $(T)=d f r$

\begin{tabular}{|c|c|c|c|}
\hline $\begin{array}{c}\text { genotype } \\
(+1-P)\end{array}$ & $\begin{array}{c}\text { number } \\
\text { harvested }\end{array}$ & $\begin{array}{l}\text { predicted } \\
\text { color(s) }\end{array}$ & $\begin{array}{l}\text { observed } \\
\text { color(s) }\end{array}$ \\
\hline$D \cdots R \ldots T \ldots$ & $\begin{array}{c}56 \\
\text { (28 red, } 28 \text { purple) } \\
\end{array}$ & $\begin{array}{l}\text { red or purple, } \\
\text { no white }\end{array}$ & \\
\hline D\# rmr Tw & $\begin{array}{c}62 \\
\text { (28 red, } 34 \text { purple) } \\
\end{array}$ & $\begin{array}{c}\text { red or purple, } \\
\text { no white }\end{array}$ & \\
\hline$D \cdots R \cdots t t t$ & $\begin{array}{c}39 \\
\text { (19 red, } 20 \text { purple) }\end{array}$ & $\begin{array}{c}\text { red or purple, } \\
\text { no white }\end{array}$ & 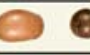 \\
\hline D- rm tttt & $\begin{array}{c}41 \\
\text { (17 white, } 24 \text { purple) }\end{array}$ & $\begin{array}{l}\text { white or purple, } \\
\text { no red }\end{array}$ & \\
\hline dddd $R \ldots$.... & $\begin{array}{c}4 \\
\text { (4 white) }\end{array}$ & all white & \\
\hline dddd rmr T... & $\begin{array}{c}22 \\
\text { (22 white) }\end{array}$ & all white & \\
\hline$d d d d R \ldots t t t$ & $\begin{array}{c}5 \\
\text { (5 white) }\end{array}$ & all white & 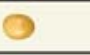 \\
\hline dddd rmr tttt & $\begin{array}{c}10 \\
\text { (10 white) }\end{array}$ & all white & \\
\hline
\end{tabular}

B

genotyping at $D$

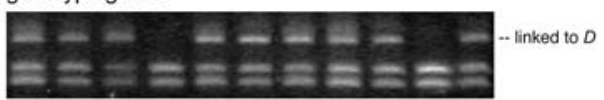

D

predicted / observed tuber color; transgene = empty vector

\begin{tabular}{|c|c|c|c|}
\hline $\begin{array}{c}\text { genotype } \\
(+1-P)\end{array}$ & $\begin{array}{c}\text { number } \\
\text { harvested }\end{array}$ & $\begin{array}{l}\text { predicted } \\
\text { color(s) }\end{array}$ & $\begin{array}{c}\text { observed } \\
\text { color(s) }\end{array}$ \\
\hline$D \ldots R \ldots T \ldots$ & $\begin{array}{c}16 \\
\text { (5 red, } 11 \text { purple) }\end{array}$ & $\begin{array}{l}\text { red or purple, } \\
\text { no white }\end{array}$ & 00 \\
\hline D. rm Tw & $\begin{array}{c}6 \\
\text { (2 white, } 4 \text { purple) }\end{array}$ & $\begin{array}{c}\text { white or purple, } \\
\text { no red }\end{array}$ & D \\
\hline$D \cdots R \cdots t t t t$ & $\begin{array}{c}12 \\
\text { (2 red, } 10 \text { purple) }\end{array}$ & $\begin{array}{l}\text { red or purple, } \\
\text { no white }\end{array}$ & \\
\hline D.- rtrr tttt & (1 white, 6 purple) & $\begin{array}{c}\text { white or purple, } \\
\text { no red }\end{array}$ & \\
\hline dddd R - T T.. & $\begin{array}{c}1 \\
\text { (1 white) }\end{array}$ & all white & \\
\hline dddd $\mathrm{rmr} T \mathrm{T-.}$ & $\begin{array}{c}5 \\
\text { (5 white) }\end{array}$ & all white & \\
\hline dddd R $\cdots$ tttt & $\begin{array}{c}4 \\
\text { (4 white) }\end{array}$ & all white & \\
\hline dddd rtrr tttt & $\begin{array}{c}3 \\
\text { (3 white) }\end{array}$ & all white & \\
\hline
\end{tabular}

Fig. 3 HPLC analysis of pigments in the varieties Chieftain, Prince Hairy, and progeny of a cross between Chieftain and transgenic Prince Hairy, where the transgene is either the 'red allele' of $d f r$ or an empty vector control
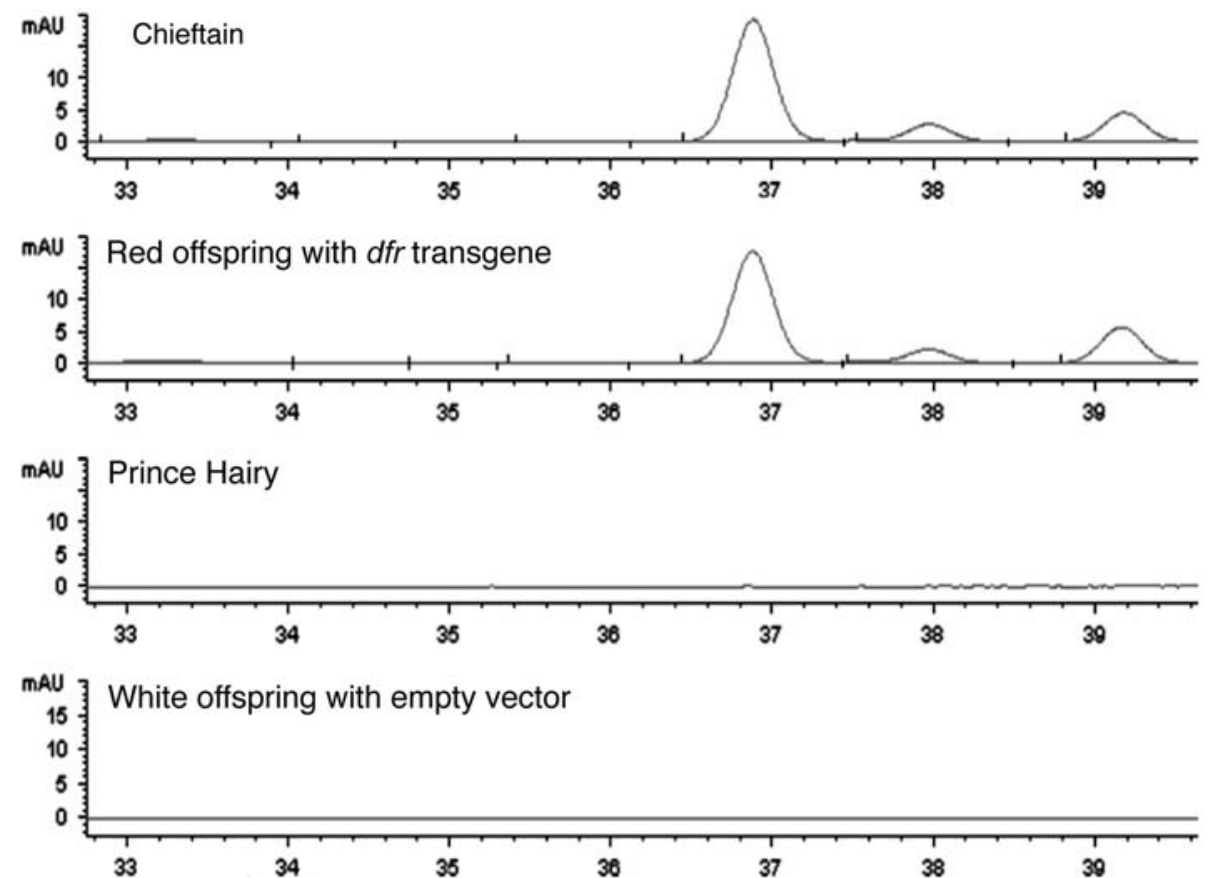

white-skinned variety Prince Hairy and a white-skinned progeny clone transformed with an empty vector, neither of which produced detectable anthocyanin (Fig. 3).

Additional characterization of tuber skin pigments by LC-MS/MS also revealed no substantial differences between Chieftain and $d f r$-transgenic (D-rrrr) tubers (Table 1). In both cases, based on the pattern of molecular mass and fragment ions, and comparison to previous potato analyses (Eichhorn and Winterhalter 2005, Naito et al. 1998, Rodriguez-Saona et al. 1998), the primary pigments were pelargonidin-3-coumaryl-rutinoside-5-glucoside, pelargonidin-3-feruloyl-rutinoside-5-glucoside, and pelargonidin-3-rutinoside-5-glucoside (Table 1). Lesser quantities of three additional anthocyanins, where peonidin took the place of pelargonidin, were also observed (Table 1). The identity of the individual anthocyanins in the two extracts was verified by comparing the $[\mathrm{M}+\mathrm{H}]^{+}$and fragmentation patterns. Prince Hairy and empty vector-transformed Prince Hairy produced no anthocyanins detectable by our LC-MS/ MS analysis (Table 1). 
Table 1 Anthocyanins detected in tubers by LC-MS/MS

\begin{tabular}{|c|c|c|c|c|c|c|c|c|}
\hline \multirow[t]{2}{*}{$\#$} & \multirow[t]{2}{*}{$R_{\mathrm{t}}(\min )$} & \multirow[t]{2}{*}{ Inferred compound } & \multirow{2}{*}{$\begin{array}{l}{[\mathrm{M}+\mathrm{H}]^{+}} \\
(m / z)\end{array}$} & \multirow{2}{*}{$\begin{array}{l}\text { Fragment ions } \\
(\mathrm{m} / \mathrm{z})\end{array}$} & \multicolumn{4}{|c|}{ Relative amount (\% peak area) } \\
\hline & & & & & Chieftain & Prince Hairy & dfr-transgenic clone & Empty vector \\
\hline 1 & 9.8 & pel-3-rut-5-glc & 741 & $579,433,271$ & 11 & $\mathrm{ND}^{\mathrm{a}}$ & 16 & ND \\
\hline 2 & 10.0 & peo-3-rut-5-glc & 771 & $609,463,301$ & 2 & ND & 2 & ND \\
\hline 3 & 14.0 & pel-3-coum-rut-5-glc & 887 & $725,433,271$ & 59 & ND & 53 & ND \\
\hline 4 & 14.1 & peo-3-coum-rut-5-glc & 917 & $755,463,301$ & 6 & ND & 4 & ND \\
\hline 5 & 14.2 & pel-3-ferul-rut-5-glc & 917 & $755,433,271$ & 17 & ND & 19 & ND \\
\hline 6 & 14.4 & peo-3-ferul-rut-5-glc & 947 & $785,463,301$ & 5 & ND & 6 & ND \\
\hline
\end{tabular}

$N D$ not detectable

\section{Discussion}

We have provided direct evidence that the potato $R$ locus codes for dihydroflavonol 4-reductase, as the allele of $d f r$ previously shown to co-segregate with the dominant allele at the $R$ locus (De Jong et al. 2003a) can transgenically complement $R$ with respect to both tuber color and anthocyanin composition.

More than one anthocyanin was observed in both Chieftain and $d f r$-transformed potato skin (Fig. 3; Table 1), consistent with previous studies that have also reported more than one anthocyanin present in red-skinned or red-fleshed tubers (Lewis et al. 1998; Naito et al. 1998; Eichhorn and Winterhalter 2005). DFR is required for the production of red, pink, and purple anthocyanins in plants (Holton and Cornish 1995; Fig. 4). It is worth noting that while only one allele of potato $d f r$ appears capable of directing the synthesis of red anthocyanins, both this and other allele(s) of potato $d f r$ appear capable of supporting the production of purple anthocyanins. As shown in Fig. 2, many potato genotypes without $R$ or the $d f r$ transgene produced purpleskinned tubers. Similarly, potatoes that are homozygous at $R$, like purple-skinned diploid W5281.2 (De Jong and Burns 1993), can produce purple anthocyanins in the presence of $P$. Thus, the key difference between 'red' and 'notred' alleles of $d f r$ does not appear to be an issue of enzyme functionality per se, as both types of alleles code for catalytically-active enzymes.

In order to produce red pelargonidin-based anthocyanins, DFR must be able to reduce DHK, while reduction of DHM is required to produce purple delphinidin or petunidin-derived compounds (Fig. 4). Thus, the enzyme encoded by the red allele of potato $d f r$ appears capable of reducing both DHK and DHM, while enzymes coded by other potato allele(s) appear capable of reducing DHM, but not DHK. The peonidin derivatives observed in Chieftain and redskinned transgenic progeny clones (Table 1) suggest that the enzyme coded by the 'red allele' of $d f r$ can also utilize DHQ as a substrate, since peonidin is simply methylated cyanidin.

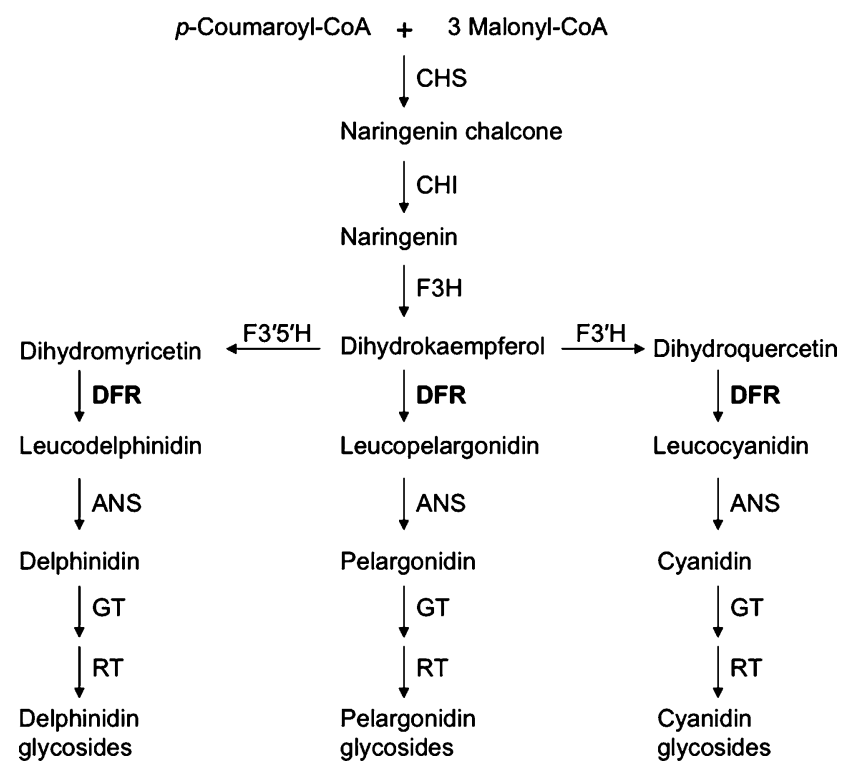

Fig. 4 Generalized anthocyanin biosynthetic pathway (adapted from Holton and Cornish 1995), illustrating the various chemical reactions that DFR can, in principle, catalyze en route to producing red (pelargonidin-based), pink (cyanidin-based), and purple (delphinidin-based) anthocyanin pigments. Enzyme abbreviations: $C H S$ chalcone synthase, $\mathrm{CHI}$ chalcone isomerase, $\mathrm{F3H}$ flavanone 3-hydroxylase, $F 3^{\prime} H$ flavonoid $3^{\prime}$-hydroxylase, $F 3^{\prime} 5^{\prime} H$ flavonoid $3^{\prime}, 5^{\prime}$-hydroxylase, $D F R$ dihydroflavonol 4-reductase, ANS anthocyanidin synthase, GT UDPglucose anthocyanidin 3-O-glucosyltransferase, $R T$ UDP-rhamnose anthocyanidin-3-glucoside rhamnosyltransferase

Transgenic expression of $d f r$ to alter color of economically important plant tissue was first reported in Petunia (Meyer et al. 1987), and has since been reported in other floral crops such as Torenia fournieri (Aida et al. 2000), rose (Katsumoto et al. 2007) and Osteospermum hybrida (Seitz et al. 2007). In a suitable genetic background, i.e., one that contains a functional allele at $D$ and lacks a functional allele at $P$, it should be possible to convert a whiteskinned potato into a red-skinned one. Of relevance to applied breeding, the red allele of $d f r$ did not appear to be silenced after sexual hybridization, as all progeny carrying $D$ and the transgene were red or purple, and never white (Fig. 2). 
It should be possible through reciprocal exchange of fragments between 'red' and 'non red' alleles of potato $d f r$ to precisely delineate the amino acids that permit the 'red allele' to utilize DHK as a substrate. Comparable experiments, exchanging portions of $d f r$ between Gerbera and Petunia, and subsequent site-directed mutagenesis (Johnson et al. 2001), have implicated a single amino acid, corresponding to potato amino acid position 145 , in the ability to utilize DHK. Potato amino acid 145 does not differ between 'red' and 'non red' alleles, although potato positions 143 and 154 are polymorphic (De Jong et al. 2003a). The crystal structure of grape DFR has recently been described (Petit et al. 2007). Thus, if the potato amino acids that influence substrate specificity can be identified, their role in influencing DFR activity could be interpreted at high resolution.

Acknowledgments This work was supported by Hatch funds provided to WD. We thank Drs. Lailiang Cheng and Pengmin Li for help with HPLC.

Open Access This article is distributed under the terms of the Creative Commons Attribution Noncommercial License which permits any noncommercial use, distribution, and reproduction in any medium, provided the original author(s) and source are credited.

\section{References}

Aida R, Kishimoto S, Tanaka Y, Shibata M (2000) Modification of flower color in torenia (Torenia fournieri Lind.) by genetic transformation. Plant Sci 153:33-42

Bongue-Bartelsman M, O’Neill SD, Tong Y, Yoder JI (1994) Characterization of the gene encoding dihydroflavonol 4-reductase in tomato. Gene 138:153-157

De Jong H, Burns VJ (1993) Inheritance of tuber shape in cultivated diploid potatoes. Am Pot J 70:267-283

De Jong WS, De Jong DM, De Jong H, Kalazich J, Bodis M (2003a) An allele of dihydroflavonol 4-reductase associated with the ability to produce red anthocyanin pigments in potato (Solanum tuberosum L.). Theor Appl Genet 107:1375-1383

De Jong WS, De Jong DM, Bodis M (2003b) A fluorogenic 5' nuclease (TaqMan) assay to assess dosage of a marker tightly linked to red skin color in autotetraploid potato. Theor Appl Genet 107:13841390

Dodds KS, Long DH (1955) The inheritance of colour in diploid potatoes: types of anthocyanidins and their genetic loci. J Genet 53:136-149

Dodds KS, Long DH (1956) The inheritance of colour in diploid potatoes: II. A three-factor linkage group. J Genet 54:27-41

Edwards K, Johnstone C, Thompson C (1991) A simple and rapid method for the preparation of plant genomic DNA for PCR analysis. Nucleic Acids Res 19:1349
Eichhorn S, Winterhalter P (2005) Anthocyanins from pigmented potato (Solanum tuberosum L.) varieties. Food Res Int 38:943-948

Forkmann G, Ruhnau B (1987) Distinct substrate specificity of dihydroflavonol 4-reductase from flowers of Petunia hybrida. Z Naturforsch 42c:1146-1148

Haq TA, Mason HS, Clements JD, Arntzen CJ (1995) Oral immunization with a recombinant bacterial antigen produced in transgenic plants. Science 268:714-716

Holton TA, Cornish EC (1995) Genetics and biochemistry of anthocyanin biosynthesis. Plant Cell 7:1071-1083

Huang Z, Mason HS (2004) Conformational analysis of hepatitis B surface antigen fusions in an Agrobacterium-mediated transient expression system. Plant Biotechnol J 2:241-249

Johnson ET, Yi H, Shin B, Oh B-J, Cheong H, Choi G (1999) Cymbidium hybrida dihydroflavonol 4-reductase does not efficiently reduce dihydrokaempferol to produce orange pelargonidin-type anthocyanins. Plant J 19:81-85

Johnson ET, Ryu S, Yi H, Shin B, Cheong H, Choi G (2001) Alteration of a single amino-acid changes the substrate specificity of dihydroflavonol 4-reductase. Plant J 25:325-333

Jung CS, Griffiths HM, De Jong DM, Cheng S, Bodis M, De Jong WS (2005) The potato $P$ locus codes for flavonoid $3^{\prime}, 5^{\prime}$-hydroxylase. Theor Appl Genet 110:269-275

Katsumoto Y, Fukuchi-Mizutani M, Fukui Y, Brugliera F, Holton TA, Karan M, Nakamura N, Yonekura-Sakakibara K, Togami J, Pigeaire A, Tao G-Q, Nehra NS, Lu C-Y, Dyson BK, Tsuda S, Ashikari T, Kusumi T, Mason JG, Tanaka Y (2007) Engineering of the rose flavonoid biosynthetic pathway successfully generated blue-hued flowers accumulating delphinidin. Plant Cell Physiol 48:1589-1600

Lewis CE, Walker JRL, Lancaster JE, Sutton KH (1998) Determination of anthocyanins, flavonoids and phenolic acids in potatoes. I: coloured cultivars of Solanum tuberosum L. J Sci Food Agr $77: 45-57$

Meyer P, Heidmann I, Forkmann G, Saedler H (1987) A new petunia flower colour generated by transformation of a mutant with a maize gene. Nature 30:677-678

Naito K, Umemura Y, Mori M, Sumida T, Okada T, Takamatsu N, Okawa Y, Hayashi K, Saito N, Honda T (1998) Acylated pelargonidin glycosides from a red potato. Phytochemistry 47:109-112

Petit P, Granier T, d' Estaintot BL, Manigand C, Bathany K, Schmitter JM, Lauvergeat V, Hamdi S, Gallois B (2007) Crystal structure of grape dihydroflavonol 4-reductase, a key enzyme in flavonoid biosynthesis. J Mol Biol 368:1345-1357

Plaisted RL, Tingey WM, Steffens JC (1992) The germplasm release of NYL 235-4, a clone with resistance to the Colorado potato beetle. Am Pot J 69:843-846

Rodriguez-Saona LE, Giusti MM, Wrolstad RE (1998) Anthocyanin pigment composition of red-fleshed potatoes. J Food Sci 63:458-465

Salaman RN (1910) The inheritance of colour and other characters in the potato. J Genet 1:7-46

Seitz C, Vitten M, Steinbach P, Hartl S, Hirsche J, Rathje W, Treutter D, Forkmann G (2007) Redirection of anthocyanin synthesis in Osteospermum hybrida by a two-enzyme manipulation strategy. Phytochemistry 68:824-833

Weigle JL, Kehr AE, Akeley RV, Horton JC (1968) Chieftain: a redskinned potato with attractive appearance and broad adaptability. Am Pot J 45:293-296 